J. clin. Path. (1949), 2, 91.

\title{
CYSTIC PNEUMATOSIS OF THE LARGE INTESTINE
}

BY

\section{FRIEDMANN}

\author{
From the Department of Pathology, Institute of Laryngology, London
}

(RECEIVED FOR PUblication, MARCH 9, 1949)

Cystic pneumatosis of the intestine is a rare condition, but perhaps not so rare as the small number of reported cases suggests. Although recognized since 1876 , when Bang first noted gas cysts in the intestine of a woman who had died of volvulus, cystic pneumatosis of the intestine has remained a baffling diagnostic problem.

The condition may be defined as the presence of gas in cyst-like formations in the body. These may be localized in any part of the gastro-intestinal tract; they have a marked predilection for the ileocaecal region and the duodenum, but are also found in the bladder, vagina, mesentery, parietal peritoneum, and pleura.

Incidence and Distribution.-Cystic pneumatosis is more common in men than in women. It occurs at all ages, but mainly between 25 and 50 . About 200 cases have been reported in the literature (Dressler, 1939 ; Sauser-Hall, 1940). Ferrandu in 1935 collected 180 cases, perhaps not all proven. Jackson in 1940 published a survey and added a case of his own, bringing the total of cases in the available literature to 172 . Of these, twelve occurred in children and 160 in adults.

Aetiology.-The aetiology of cystic pneumatosis is obscure and none of the theories advanced is entirely convincing. Theories of a neoplastic or a chemical origin of cystic pneumatosis can be disregarded. The clinical picture of the reported cases is also unlike that of a gas-forming infection, the tissue reactions are not suggestive of an inflammatory condition, and bacterial cultures are usually negative. Animal experiments (SauserHall, 1940) have produced no evidence in support of a bacterial origin.
The mechanical hypothesis postulates a break in the intestinal mucosa through which gas is forced into the intestinal wall. The defect can be caused by a localized infection or over-distension of the intestine by gas. There is some evidence in support of this view. In a large proportion of cases cystic pneumatosis is associated with ulcerative diseases of the gastro-intestinal tract, with obstruction and hyperperistalsis-for example, duodenal ulcer and pyloric stenosis, intestinal tuberculosis, chronic ileus caused by adhesions, etc. This theory, however, fails to explain the generalized forms, and the fact that not all people with pyloric stenosis develop cystic pneumatosis. Dressler (1939) suggests that there may be a constitutional weakness in the walls of the lymphatics which enables a comparatively slight rise in the abdominal pressure to cause a dilatation of the lymphatics.

Pathology.-The gross pathology depends on the extent of the gaseous infiltration. As a rule the bowel is covered with grape-like cysts varying in size, shape, and number. They can be localized in all strata of the intestinal wall, usually in the submucosa and in the subserous tissue. Moore (1929) says that in children gas is formed mainly in the mucosa and submucosa, but in adults the gas accumulates in the subserosa. Microscopically the cysts are separated by loose connective tissue lined by endothelial cells resembling the endothelial cells of the lymphatics; or they may show no lining at all. Giant cells of the foreign-body type are a fairly common feature. The cysts may be empty or may contain some serous material. Haemorrhage, oedema, and eosinophil cells have been described in the interstitial tissue. 
FIG. 1.-Under the intact mucosa the submucosa is transformed into a system of numerous cyst-like cavities resembling emphysema of the lungs. $\times 20$.

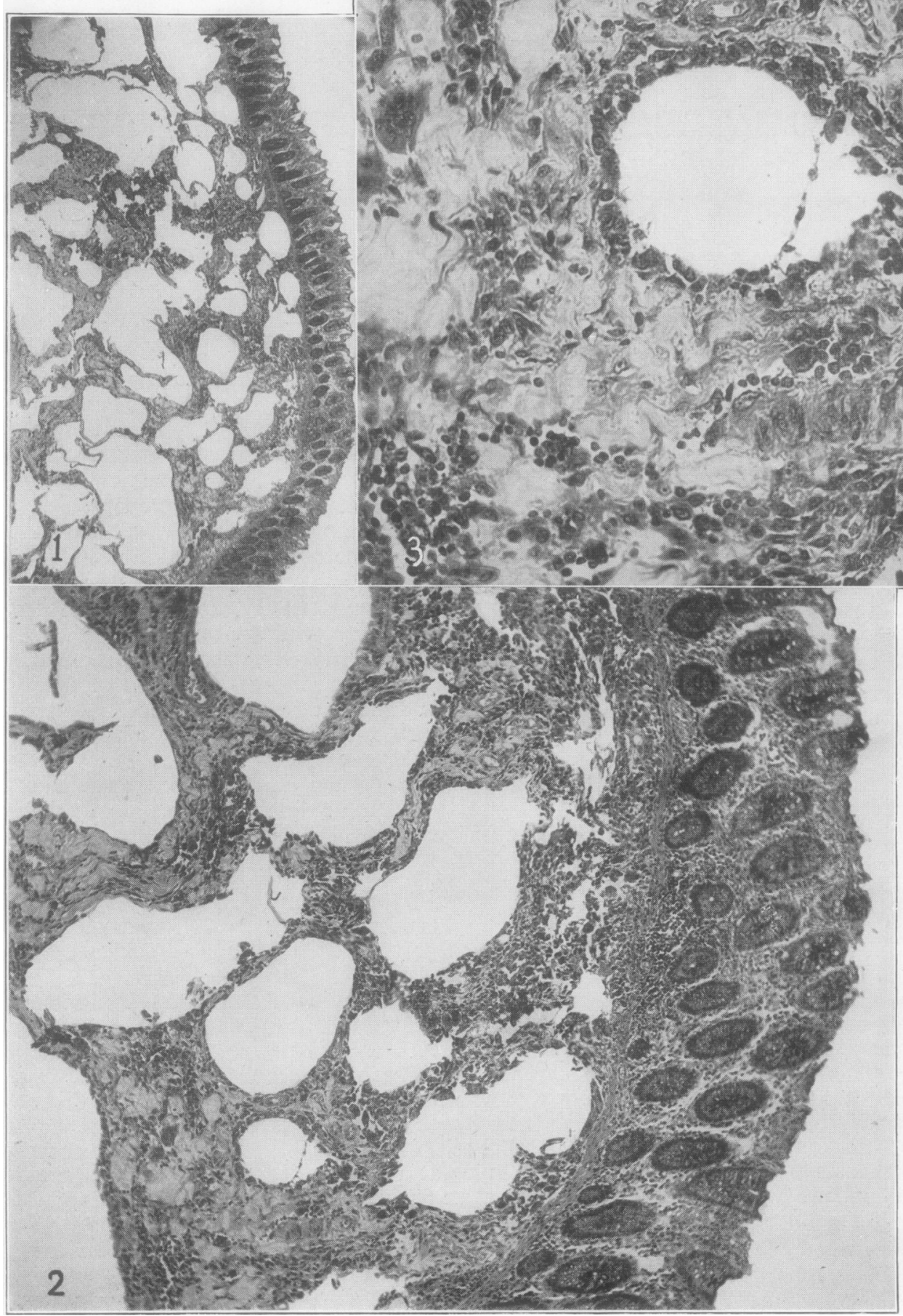

1

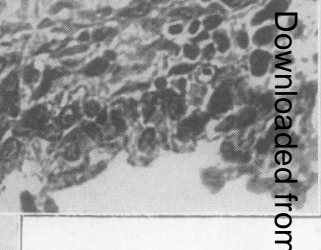

Fig. 3.-Shows cytological de more clea $\times 235$.

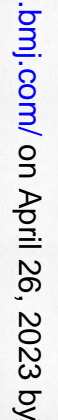

FIG. 2,-The cavios are lined by er thelial and num ous giant ד্th of foreign-b $\frac{\text { (ब) }}{\mathrm{d}}$ y type, which $\frac{\Omega}{\mathbb{D}}$ also be seen 1 ำ freely in the $\sigma$ connective ti̊̊ue separating cavities. $\times 8$ 
Clinical Picture.-Primary cystic pneumatosis unassociated with an organic change in the abdomen is rare (Urban, 1937). According to various authors, in 45 to 75 per cent of all cases reported cystic pneumatosis was associated with a stenosing duodenal ulcer. The clinical diagnosis of cystic pneumatosis is very difficult (Reverdin, 1924), most cases so far reported having been recognized only at operation or at necropsy. Mengis (1938) considers sudden severe abdominal pain the leading clinical symptom of cystic pneumatosis. Recently, however, several cases have been diagnosed by radiography (Lerner and Gazin, 1946 ; Berglund, 1939).

Cystic pneumatosis of the intestine is in itself a benign process, and the cysts may be very quickly absorbed. Surgical treatment, if necessary, should therefore be directed against the underlying disease, but there is no need for drastic resection of the cystic intestine.

Pelnár (1900) described a case of cystic pneumatosis associated with tuberculosis of the intestine. Barták (1941) reported on the histology of a case of cystic pneumatosis of the caecum which was surgically removed. More recently Vahala (1946) described in some detail another case of cystic pneumatosis of the caecum in which the patient, a 44-year-old physician, was admitted to hospital with a diagnosis of acute appendicitis. He had been suffering for years with occasional bouts of pain in the lower abdomen which came on after exertion but subsided in a few days without treatment. At operation the appendix appeared normal, but the caecum was studded with grapelike cysts in the serosa and deeper in the caecal wall. In this patient the underlying condition was a chronic duodenal ulcer, and the cystic pneumatosis may have been provoked by a mild attack of enteritis.

In the present case, too, the clinical picture was misleading and suggestive of malignant growth of the large intestine.

\section{Case Report}

An undernourished woman of 65 was admitted to a provincial hospital with a long history of indigestion and constipation. She had recently been losing much weight. A movable lump, the size of a man's fist, was found on palpation in the ileocaecal region, and malignant growth of the large intestine was suspected. At laparotomy the caecum and ascending colon were found to be transformed into a grape-like mass that showed many partly pedunculated vesicles which collapsed when they were cut open. There was no malignant growth, and the affected parts were resected.
The patient developed bronchopneumonia and died soon after the operation. Necropsy could not be performed.

Histology.-Three small pieces were excised from the ascending colon and fixed in formalin. No bacteriological or chemical examination could be carried out. The macroscopical appearance of the specimens was characteristic: the cut surface showed small round or oval cavities 1 to $3 \mathrm{~mm}$. in diameter situated in the intestinal wall. The consistency of the specimens was sponge-like, not unlike emphysematous lung tissue, and the cavities appeared empty.

Seçtions stained with haematoxylin and eosin showed the glands to be unchanged and no signs of inflammation in the mucosa (Fig. 1). Closely arranged cystic cavities, varying in size and shape, occupied the whole intestinal wall. They were separated by slightly oedematous connective tissue, and some were lined by fairly large endothelial cells. Others showed flat cells only, or no lining at all. Numerous giant cells of foreign-body type lined some of the cysts; more often they lay freely in the loose connective tissue of the submucosa. Round, small cysts were seen close to the glandular surface, larger ones in the deeper layers. Some of these seemed to have been formed by fusion of two or more smaller cysts under pressure (see the "torn" wall in the larger cyst, Fig. 2). There were a few round cells, but no tuberculous or ulcerative changes and no signs of malignancy.

Most of the cavities were empty. Some contained a faintly blue-staining homogeneous material. In sections stained for fat some red-staining material was seen in a few cysts.

\section{Discussion}

This case demonstrates how numerous are the disguises under which cystic pneumatosis of the intestine may occur. As in other cases, there was a long history of dyspepsia and constipation. The exact origin of these signs could not be established. The tumour-like mass was entirely formed by the cystic caecum and ascending colon. The cysts were located in all the layers of the intestinal wall, and they collapsed when incised. They contained some serous and fatty material. This might suggest that the cysts were formed from distended lymphatics. As Lamont (1929) points out, the anatomical arrangement of the lymphatics, which form a complicated series of plexuses, would be quite compatible with the tier-like arrangement of the cysts. Dressler (1939) assumes that the cysts are formed within the lymphatics.

The case was typical in that it simulated another disease-malignant growth-and was only recognized at operation. Its occurrence in an elderly woman was unusual. 


\section{Summary}

A case of cystic pneumatosis of the large intestine in a woman aged 65 , simulating symptoms and signs of malignant growth, is described.

My thanks are due to Mr. E. V. Wilmott, F.R.P.S., who prepared the photomicrographs, and to Dr. A. E. Rides, medical adviser, British Council in Prague, for valuable literature.

\section{REFERENCES}

Achmatowicz, L. (1936). Zbl. Chir., 63, 1585.

Bang, B. L. F. (1876). Nord. med. Ark., 8, No. 18, p. 1.

Barták, F. (1941). Shornik lek., 41, 317.
Baumann-Schenker, R. (1939), Acta radiol., Stockh., 20, 365.

Baumgartner, O. (1943). Helvet. med. acta, 10, 771.

Berglund, S. (1939). Acta radiol., Stockh., 20, 401.

Davies, S. T. (1941). Ind. med. Gaz., 76, 94.

Dressler, M. (1939). Helvet. med. acta, 6, 229.

Ferrandu, S. Quoted by Dressler.

Jackson, J. A. (1940). Surg. Gynec. Obstet., 71, 675.

Jackson, J. A. (1940). Surg. Gynec. Obstet., 71, 675.
Lamont, D. (1929). Trans. R. Med. Chir. Soc. Glasgow, 23, 113.

Lamont, D. (1929). Trans. R. Med. Chir. Soc. Glasgow, 23, 113. Lindsay, J. W., Rice, E. C., and Selinger, M. A. (1940). Arch. Path

Mengis, O. (1938). Radiol. Rschr., 7, 222.

Moore, R. A. (1929). Amer. J. Dis. Child., $38,818$.

Pelnă, J. (1900). Rozpravy ces. akademie, 9, 12 . Quoted by Vahalẩ

Reverdin, A. (1924). Rev. méd. Suisse rom., 545.

Sauser-Hall, E. (1940). Gastroenterologia, 65, 193 and 313

Tribedi, P. B. (1941). Calcutta med. J., 38, 285.

Urban, H. (1937). Fschr. Röntgenstr., 65, 231.

Vahala, Z. (1946). Cas. ces. lek., 85, 1257. 